\title{
Lithium Insertion to Iron-substituted Molybdenum Trioxide
}

\author{
Tadashi SENOH* ${ }^{*}$, Takayuki MUKAE, Takashi MIURA \\ and Tomiya KISHI
}

Received December 20, 1993 ; Accepted April 11, 1994

\begin{abstract}
Changes in the lithium insertion characteristics by introducing the inhomogeneity to $\alpha-\mathrm{MoO}_{3}$ having a van der Waals layer gap were investigated. The partially iron-substituted $\alpha-\mathrm{MoO}_{3}$ was prepared by the solid state reaction of $\alpha-\mathrm{MoO}_{3}$ and $\mathrm{Fe}_{2} \mathrm{O}_{3}$ powders. $\mathrm{X}$-ray diffraction and infrared spectroscopic results showed that a solid solution of iron-substituted $\alpha-\mathrm{MoO}_{3}$, having the same lattice structure and bonding state as $\alpha-\mathrm{MoO}_{3}$, existed up to an atomic fraction of $\mathrm{Fe} /(\mathrm{Mo}+\mathrm{Fe})=c a .0 .1$. After chemical lithiation of both $\alpha-\mathrm{MoO}_{3}$ and iron-substituted $\alpha-\mathrm{MoO}_{3}$, a discontinuous change of the interlayer distance was observed at around the composition of $x(=\mathrm{Li} / \mathrm{Mo}$ or $\mathrm{Li} /(\mathrm{Mo}+\mathrm{Fe}))=c a .0 .2$. At $x>0.2$, a larger interlayer expansion in iron-substituted $\alpha-\mathrm{MoO}_{3}$ than in $\alpha-\mathrm{MoO}_{3}$ occurred probably due to the difference in van der Waals force. By substituting $\mathrm{Mo}$ with $\mathrm{Fe}$ in $\alpha-\mathrm{MoO}_{3}$, the open-circuit potential became higher and the discharge capacity increased considerably at the same time.
\end{abstract}

\section{INTRODUCTION}

As a possible cathode material for lithium secondary cells which are expected as a high energy density power source for many portable electronic apparatus or as a load levelling battery, various transition metal chalcogenides with van der Waals layer gap were so far examined. However, they are easily suffered from irreversible lattice change upon lithium insertion because the layers are bound weakly. In order to avoid the irreversible lattice change and to improve the charge-discharge cycling efficiency, much attempts have been proposed ${ }^{1)}$ to substitute with foreign transition metal or to introduce ionic character to the interlayer bonding.

Orthorhombic molybdenum trioxide, $\alpha-\mathrm{MoO}_{3}$, with layered lattice structure has attracted much attention as a possible intercalation cathode material for a lithium secondary cell and lithium insertion to this oxide has been investigated by many researchers. Besenhard $e t$ $a l^{2)}$ discussed that structural and transport properties of lithiated $\mathrm{MoO}_{3}$ showed the correlation between the lattice expansion and the chemical diffusion coefficient of lithium. On the other hand, amorphous $\mathrm{MoO}_{3}$ has a larger capacity and better reversibility in charge-discharge cycling as compared with crystalline $\mathrm{MoO}_{3}{ }^{3)}$. Among these approaches, Julien et al. ${ }^{4)}$ suggested that oxygen vacancies introduced upon the preparation of $\mathrm{MoO}_{3}$ films affected lithium insertion reaction.

In this work, as an attempt to improve the characteristics of $\mathrm{MoO}_{3}$ as an insertion host having van der Waals gap, Mo was partially substituted with $\mathrm{Fe}$ and the chemical lithiation of iron-substituted $\alpha-\mathrm{MoO}_{3}$ was investigated comparatively with that of $\alpha-\mathrm{MoO}_{3}$.

Department of Applied Chemistry, Faculty of Science and Technology, Keio University (Hiyoshi 3-14-1, Kouhoku-ku, Yokohama, 223 Japan)

Key Words : Molybdenum Trioxide, $\mathrm{MoO}_{3}$, Iron Substitution, Lihtium Secondary Cell

\section{EXPERIMENTAL}

2.1 Preparation of iron-substituted $\alpha-\mathrm{MoO}_{3}$

Iron-substituted $\alpha-\mathrm{MoO}_{3}$ was prepared by the solid state reaction of $\alpha-\mathrm{MoO}_{3}$ (Soekawa 99.9\%) and $\mathrm{Fe}_{2} \mathrm{O}_{3}$ (Kanto-Kagaku, 99.0\%). The mixture was heated at $500^{\circ} \mathrm{C}$ in air for 120 hours in a platinum crucible and then quenched. $\alpha-\mathrm{MoO}_{3}$ powders as a reference material was also treated by the same method.

2.2 Chemical lithium insertion

Chemical lithiation was carried out by using a butyllithium ( $n$-BuLi) (Kanto Kagaku, $1.6 \mathrm{~mol} \cdot \mathrm{dm}^{-3}$ solution in hexane) as a reducing agent. Both iron-substituted $\alpha-\mathrm{MoO}_{3}$ and $\alpha-\mathrm{MoO}_{3}$ powders were lithiated by $0.06 \mathrm{~mol} \cdot \mathrm{dm}^{-3} n$-BuLi/hexane solution at room temperature for 1-170 hour in a glass tube filled with $\mathrm{N}_{2}$ gas. The extent of chemical lithiation, $x=\mathrm{Li} /(\mathrm{Mo}+\mathrm{Fe})$ or $\mathrm{Li} /$ Mo, was determined by atomic absorption analysis for $\mathrm{Li}$, where lithiated samples were dissolved in hot concentrated sulfuric acid and then diluted with distilled water.

\subsection{Analytical procedures}

Powder X-ray diffraction (XRD) patterns were obtained using Rigaku diffractometer ( $\mathrm{Rad}=\mathrm{C}$ or Rint1300) with a monochromatized $\mathrm{Fe} K_{\alpha}$ radiation $(\lambda=$ $1.9357 \AA$ ) in the presence of the inner standard of an $\mathrm{Si}$ powder.

Infrared (IR) spectra were obtained at room temperature within a range of $400-1200 \mathrm{~cm}^{-1}$ with a $\mathrm{KBr}$ disk method using an FT - IR spectrometer (Bio-Rad, FTS65), where all samples were dried in vacuo for 1 hour just before the measurement.

Any changes in XRD patterns and IR spectra of lithiated samples during the analyses were not observed.

\subsection{Electrochemical measurements}

Sample electrode disks of $5 \mathrm{~mm}$ in diameter and 20 $30 \mathrm{mg}$ in weight were made from a mixture of $80 \%$ active material, $10 \%$ acetylene black and $10 \%$ poly(tetrafluoroethylene) (PTFE). The mixture was pressed onto an $\mathrm{Ni}$-mesh at a pressure of $2 \times 10^{6} \mathrm{~Pa}$ for 2 min and the Ni-mesh was connected to a copper wire with silver paste. The edge and the back faces were cov- 


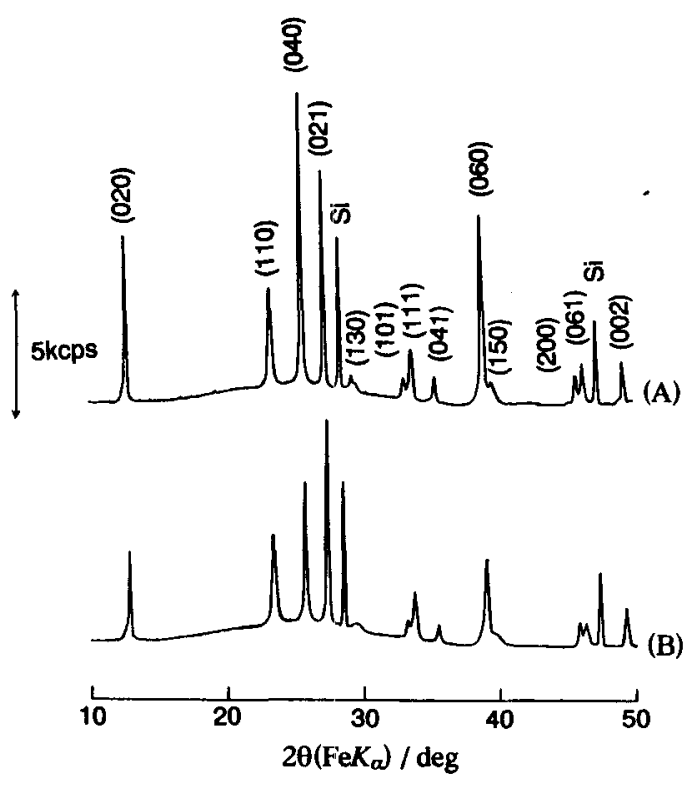

Fig. 1 Typical powder XRD patterns of (A) $\alpha-\mathrm{MoO}_{3}$ and (B) $\mathrm{Fe}_{y} \mathrm{Mo}_{1-y} \mathrm{O}_{3}(y=0.1)$.

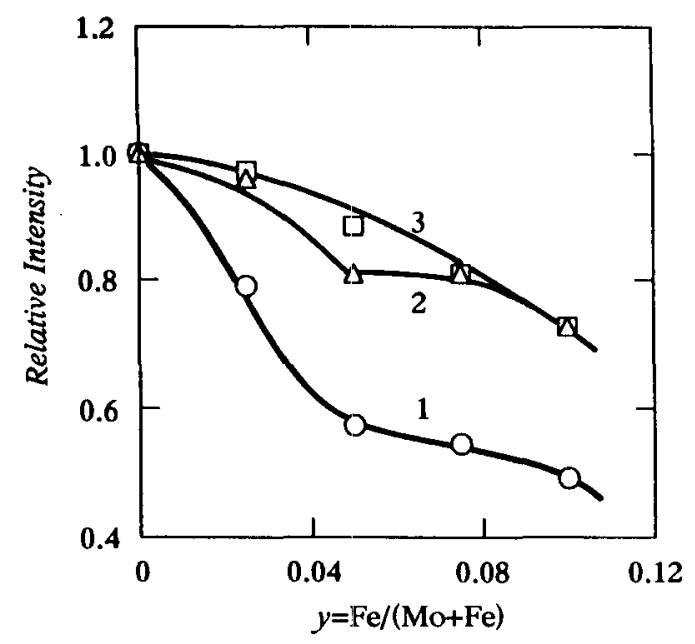

Fig. 2 Changes in the relative intensity of typical XRD peaks with $y$.

$$
1: I_{(020),} \quad 2: I_{(200),} \quad 3: I_{(002)}
$$

ered with silicon rubber. $A$ beaker type cell was constructed in a dry box, where an $\mathrm{Li}$ counter electrode, another $\mathrm{Li}$ reference electrode and a $1 \mathrm{~mol} \cdot \mathrm{dm}^{-3} \mathrm{LiClO}_{4} /$ propylene carbonate (PC) electrolyte solution were employed at $25^{\circ} \mathrm{C}$.

\section{RESULTS AND DISCUSSION}

3.1 Crystal structure and bonding state of iron-substituted $\alpha-\mathrm{MoO}_{3}$

Typical powder XRD pattern of $\mathrm{Fe}_{y} \mathrm{Mo}_{1-\mu} \mathrm{O}_{3}(y=0.1)$
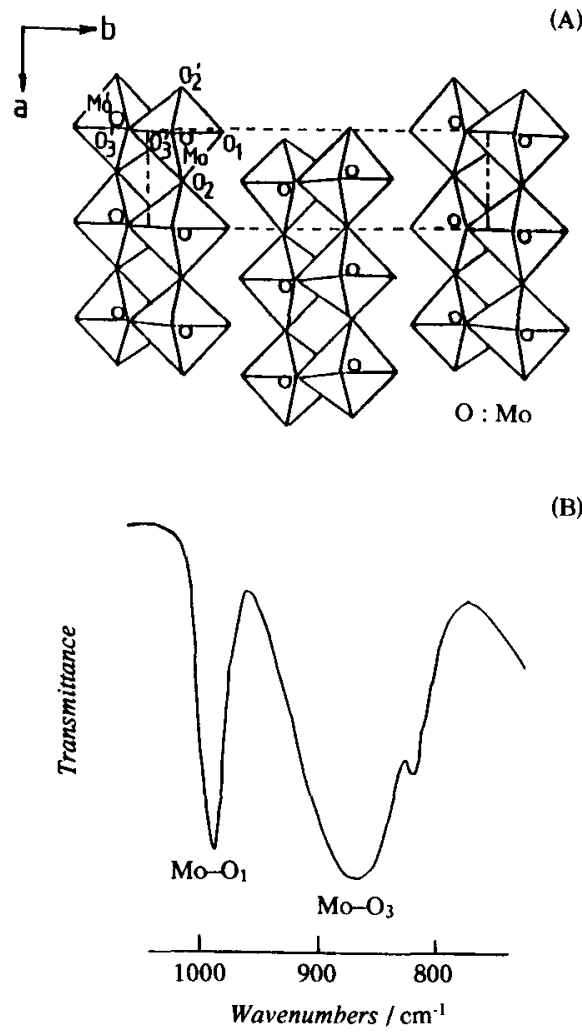

(B)

Fig. 3 (A) Lattice structure of $\alpha-\mathrm{MoO}_{3}$ and (B) $v$ (Mo-O) IR absorption bands.

is compared with that of $\alpha-\mathrm{MoO}_{3}$ mother in Fig. 1. The original XRD pattern of $\alpha-\mathrm{MoO}_{3}$ is maintained and any new diffraction peak is not found at $y<0.1$, whereas several peaks attributable to $\mathrm{Fe}_{2} \mathrm{O}_{3}$ or $\mathrm{Fe}_{2}\left(\mathrm{MoO}_{4}\right)_{3}$ appear at $0.1<y$. These results show that the substitution of Mo with Fe occurs without changing a mother lattice of $\alpha$ $\mathrm{MoO}_{3}$ within a composition range of $0 \leq y \leq 0.1$, where the lattice parameters remain almost constant (within $0.1 \%$ ). The relative intensity of an $(h k l)$ peak of the ironsubstituted sample to that of $\alpha-\mathrm{MoO}_{3}$ mother, on the other hand, decreases with increasing $y$ as can be seen in Fig. 2. Especially, the (020) peak becomes weaker remarkably with increasing $y$ suggesting that the lamellar structure is disordered by replacing Mo with Fe. When we consider the valence of these cations, the oxygen vacancy should be introduced because Mo(VI) ions are substituted with Fe(III). Accordingly, iron-substituted samples should be designated as $\mathrm{Fe}_{y} \mathrm{Mo}_{1-y} \mathrm{O}_{3-\delta}$ where $\delta=(3 / 2) y$.

Less steep change in relative intensity with $y$ at $x>0.05$ may be a result of additional formation of vacancy at another sites than $O_{1}$, but detailed analysis must be necessary (see also Fig. 4). 


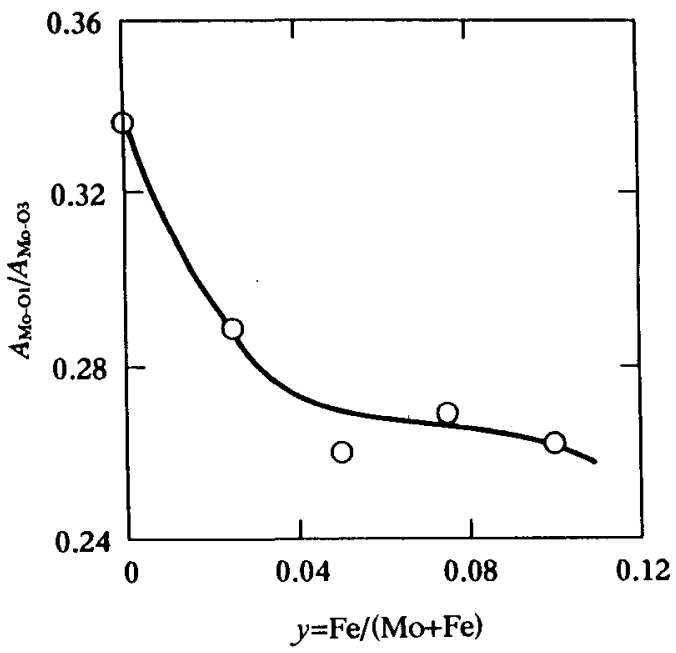

Fig. 4 A change in the relative IR absorption intensity of $A_{\mathrm{MaO}-\mathrm{Ol}} / A_{\mathrm{MaO}}$ with $y$.

The crystal structure and IR spectrum of $\alpha-\mathrm{MoO}_{3}$ are given in Fig. 3, where two absorption bands at around 1000 and $870 \mathrm{~cm}^{-1}$ are assigned to $v\left(\mathrm{Mo}-\mathrm{O}_{1}\right)$ and $v(\mathrm{Mo}-$ $\mathrm{O}_{3}$ ) stretching modes, respectively ${ }^{6}$. Most absorption bands for iron-substituted sample are almost identical to those for $\alpha-\mathrm{MoO}_{3}$. As seen in Fig. 4, however, the relative absorbance of $A_{(\mathrm{MO}-\mathrm{O} 1)} / A_{\left(\mathrm{MoO}_{\mathrm{O}}\right)}$ decreases with increasing $y$, suggesting that the concentration of oxygen facing to van der Waals gap $\left(\mathrm{O}_{1}\right)$ decreases with increasing $y$ and therefore that the oxygen vacancy is introduced preferentially at $\mathrm{O}_{1}$ sites at least up to $y=0.05$. Therefore, iron substituted $\mathrm{Fe}_{y} \mathrm{Mo}_{1-y} \mathrm{O}_{3}$ with $y=0.05$ is used as an host material for lithium insertion. 3.2 Lithiation of $\alpha-\mathrm{MoO}_{3}$ and $\mathrm{Fe}_{y} \mathrm{Mo}_{1, y} \mathrm{O}_{3-\delta}$

Figure 5 shows the open-circuit potential of chemically lithiated samples as a function of $x$. For $\alpha-\mathrm{MoO}_{3}$ the open-circuit potential lowers gradually with increasing $x$ showing a small hump at about $x=0.2$, while for $\mathrm{Fe}_{y} \mathrm{Mo}_{1-\gamma} \mathrm{O}_{3-\delta}$ the potential plateau at $3.35 \mathrm{~V}$ lies in a region of $0.2<x<0.5$ and the potential drops sharply at $x=0.5$. Changes in these dependencies at about $x=0.2$ will be related with the fact that structural changes occur at about $x=0.2$, as mentioned below (see Fig. 8). Hence, the chemical potential of lithium is different in these two host materials, probably because the coordination state of $\mathrm{Li}^{+}$ion in $\mathrm{Fe}_{y} \mathrm{Mo}_{1-y} \mathrm{O}_{3-\delta}$ differs from that in $\alpha-\mathrm{MoO}_{3}$. Since $x$ value corresponding to the plateau region is considerably larger than $y$ value, substituting $\mathrm{Fe}$ ions are hardly considered to affect the coordination of $\mathrm{Li}^{+}$ions directly.

The analogous potential difference between $\mathrm{Fe}_{y} \mathrm{Mo}_{1}$. ${ }_{y} \mathrm{O}_{3-\delta}$ and $\alpha-\mathrm{MoO}_{3}$ host materials can be found out during galvanostatic discharge at $0.1 \mathrm{~mA} \cdot \mathrm{cm}^{-2}$ as shown in Fig. 6. Iron-substituted samples have a characteristic

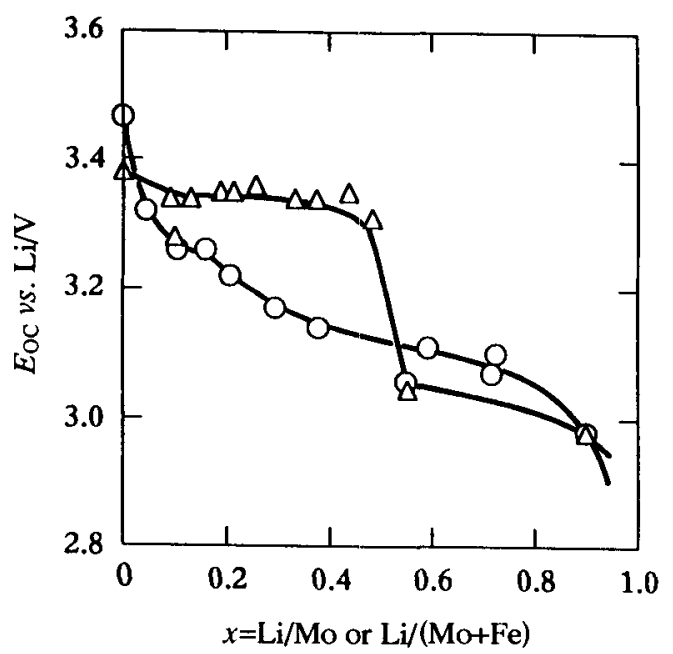

Fig. 5 The open-circuit potentials of chemically lithiated $\mathrm{Li}_{x} \mathrm{MoO}_{3}(\mathrm{O})$ and $\mathrm{Li}_{x} \mathrm{Fe}_{y} \mathrm{MoO}_{1-y} \mathrm{O}_{2-\delta}(\Delta)(y=0.05)$.

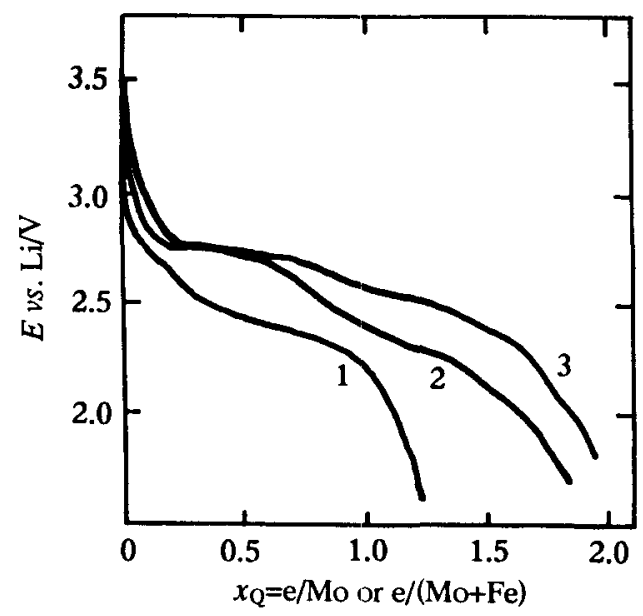

Fig.6 Galvanostatic discharge curves at $0.1 \mathrm{~mA} \cdot \mathrm{cm}^{-2}$ $1: y=0\left(\alpha-\mathrm{MoO}_{3}\right), \quad 2: y=0.05, \quad 3: y=0.10$.

potential plateau and much discharge capacity than $\alpha-$ $\mathrm{MoO}_{3}$ at the same time. Curve 1 in this figure is in good agreement with a reported ${ }^{4)}$ data for $\alpha-\mathrm{MoO}_{3}$.

As reported by Besenhard et al. $^{3)}$, the crystallinity of $\alpha-\mathrm{MoO}_{3}$ is lowered by electrochemical or chemical lithiation owing to the week bonding across van der Waals layer gap. In the present work, considerable intensity decrease and broadening of XRD peaks are observed, and some XRD peaks corresponding to different interlayer distances appear at the same time. Chemically lithiated samples were heat-treated at $150^{\circ} \mathrm{C}$ in vacuo for 1 hour in order to investigate the stable phases in more detail.

As can be seen in Fig. 7, only a few XRD peaks re- 


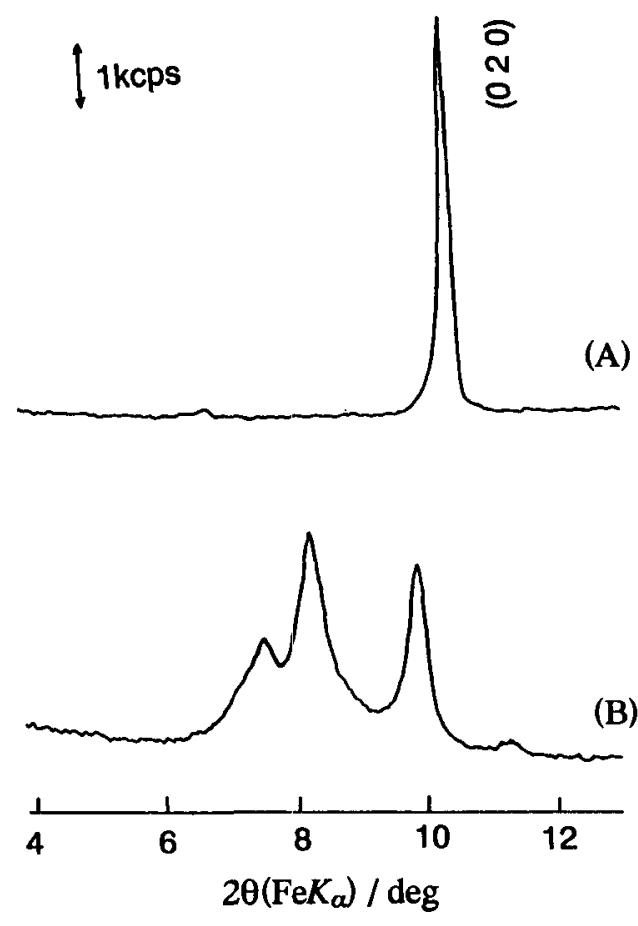

Fig. 7 Powder XRD patterns of (A) $\alpha-\mathrm{MoO}_{3}$ and (B) chemically prepared $\mathrm{Li}_{0.3} \mathrm{MoO}_{3}$.

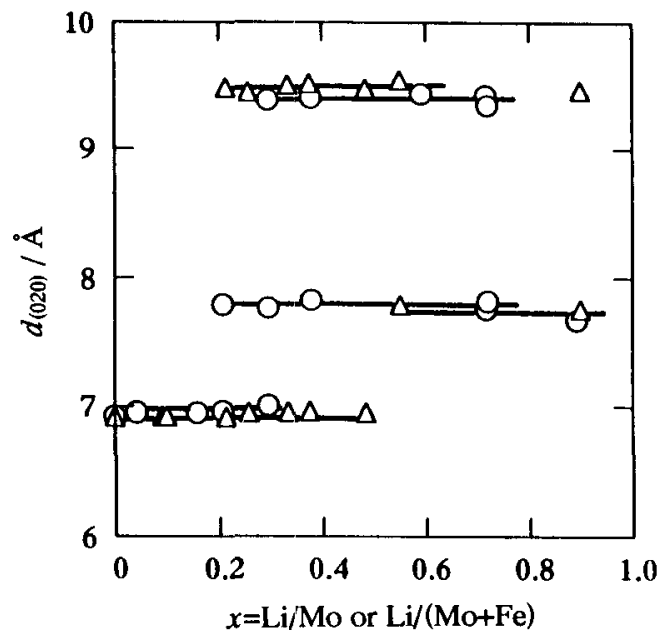

Fig. 8 The interlayer distance of $d_{(020)}$ after chemical lithiation of $\alpha-\mathrm{MoO}_{3}(\mathrm{O})$ and $\mathrm{Fe}_{y} \mathrm{Mo}_{1-y} \mathrm{O}_{3-\delta}(\Delta) \quad(y=0.05)$.

main after heat-treatment of lithiated samples. When the lines at around $2 \theta=10^{\circ}$ are assumed as $(020)$ reflections from respective new phases, their (040) and (060) family lines can be found out at a higher $2 \theta$ region. Thus, several phases having different basal spacings are considered to be formed upon chemical lithiation.

The interlayer distance and the intensity of these

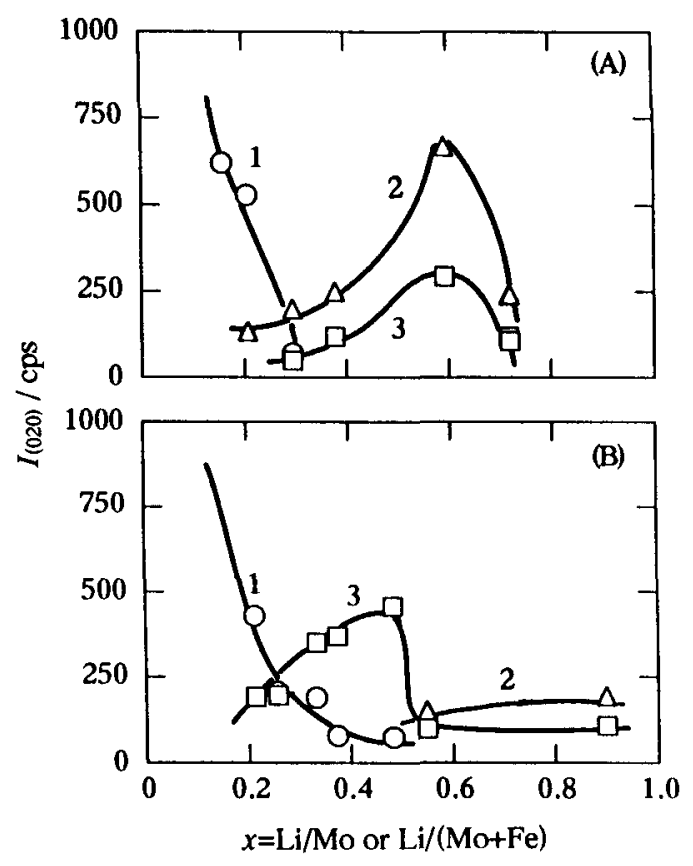

Fig. 9 The intensity of XRD peaks from chemically lithiated (A) $\alpha-\mathrm{MoO}_{3}$ and (B) $\mathrm{Fe}_{y} \mathrm{Mo}_{1-y} \mathrm{O}_{3-\delta}(y=0.05)$.

1: $d=c a .6 .9 \AA, 2: d=c a .7 .8 \AA, 3: d=c a .9 .4 \AA$

(020) XRD lines are shown in Fig. 8 and Fig. 9, respectively, as functions of $x$. Within a range of $0<x<0.2$, lithiated $\alpha-\mathrm{MoO}_{3}$ is a single phase solid solution whose $d_{(020)}$ is almost independent of $x . I_{(020)}$, however, decreases remarkably with increasing $x$ and this fact may correspond to the continuous lowering of the open-circuit potential in this range of $x$. Similar results are obtained for lithiated $\mathrm{Fe}_{2} \mathrm{Mo}_{1-y} \mathrm{O}_{3-\delta}$ and the original interlayer distance of $\alpha-\mathrm{MoO}_{3}(\mathrm{ca} .6 .9 \AA)$ does not change at $0<x<0.2$. It is probable that inserted $\mathrm{Li}^{+}$ions are accommodated in the intralayer site at $0<x<0.2$ as is the case for proton insertion ${ }^{7)}$.

At $x>0.2$, a new phase having the interlayer gap of ca. $7.8 \AA$ appears discontinuously for an $\alpha-\mathrm{MoO}_{3}$ host. $\mathrm{Li}^{+}$ions are inserted probably into this wider interlayer gap than original one. Similar expansion of interlayer gap was reported by Besenhard et al ${ }^{3)}$ and Dmitrienko et $a l^{8)}$, although they regarded the expansion as continuous. It is plausible from the present XRD data that discontinuous changes in the interlayer gap due to lithiation take place in case of $\alpha-\mathrm{MoO}_{3}$.

On the other hand, for $\mathrm{Fe}_{y} \mathrm{Mo}_{1-y} \mathrm{O}_{3-\delta,}$ another phase with interlayer gap of $c a .9 .5 \AA$ forms mainly at $0.2<x<0.5$ and $\mathrm{Li}^{+}$ions are expected to be inserted to this gap. The difference of the second phase preferentially formed by lithiation at $0.2<x<0.5$ might be due to the different oxygen coordination of $\mathrm{Li}^{+}$ions in the interlayer gap. It is probable that the difference is re- 
(A)

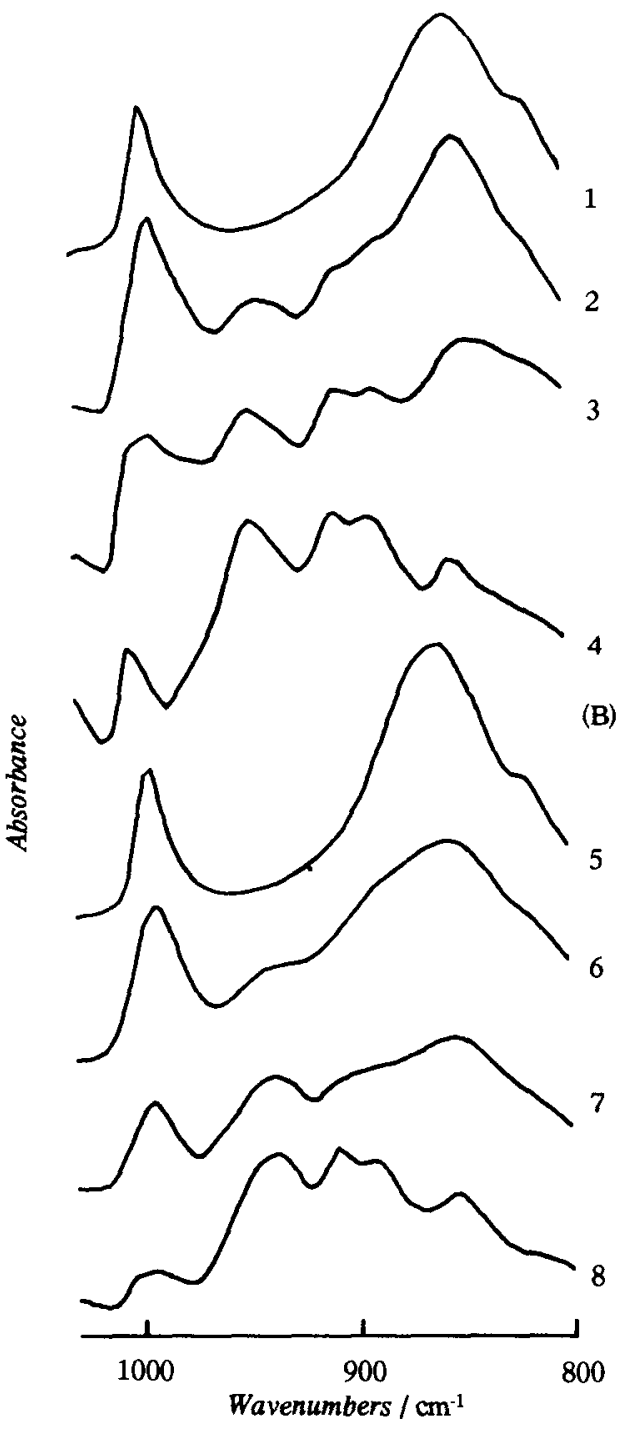

Fig. 10 IR spectra of (A) $\mathrm{Lik}_{\mathrm{k}} \mathrm{MoO}_{3}$ and $\mathrm{Li}_{x} \mathrm{Fe}_{y} \mathrm{MOO}_{1-y} \mathrm{O}_{3-\delta}$ $(y=0.05)$.

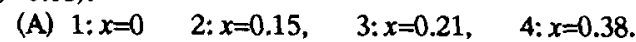

(B) $5: x=0, \quad 6: x=0.13, \quad 7: x=0.21, \quad 8: x=0.38$.

lated to the concentration of oxygen vacancy facing to the interlayer gap. The larger (020) expansion at $0.2<x<0.5$ may arise from the weaker van der Waals force owing to the existence of oxygen vacancies, and more flat open-circuit potential will be caused by an apparent strain-mediated attractive interaction between guest ions in the interlayer channels?).

IR spectra of lithiated $\mathrm{Fe}_{y} \mathrm{Mo}_{1-y} \mathrm{O}_{3-\delta}$ and $\alpha-\mathrm{MoO}_{3}$ are in Fig. 10(A) and (B), respectively. In both cases, $v(\mathrm{Mo}-$ $\left.\mathrm{O}_{1}\right)$ and $v\left(\mathrm{Mo}-\mathrm{O}_{3}\right)$ peaks do not shift substantially at $0<\mathrm{x}<0.2$, though $A_{(\mathrm{Mo}-03)}$ decrease preferentially with increasing $x$, suggesting that inserted $\mathrm{Li}^{+}$ions probably interact not with $O_{1}$ facing to van der Waals gap but mainly with $\mathrm{O}_{3}$. At $0.2<x$, on the other hand, $A_{(M o-01)}$ decreases characteristically and new absorption bands appear at a smaller wavenumber region than original $v\left(\mathrm{Mo}-\mathrm{O}_{1}\right)$. The fact that the slight shift of $v\left(\mathrm{Mo}-\mathrm{O}_{1}\right)$ to a larger wavenumber is observed only for $\alpha-\mathrm{MoO}_{3} \mathrm{im}-$ plies that the effect of inserted $\mathrm{Li}^{+}$ions is stronger in $\alpha$ $\mathrm{MoO}_{3}$ than in $\mathrm{Fe}_{y} \mathrm{Mo}_{1 . y} \mathrm{O}_{3-\delta}$.

The appearance of new IR absorption bands should correspond to the formation of new phases detected by XRD measurements. Detail analyses of the lattice position of inserted $\mathrm{Li}^{+}$ions, the concentration of oxygen vacancy and so on have to be done using other sensitive techniques.

\section{CONCLUSIONS}

$\mathrm{Mo}$ (VI) in $\alpha-\mathrm{MoO}_{3}$ can be substituted with $\mathrm{Fe}$ (III) up to an atomic fraction of $\mathrm{Fe} /(\mathrm{Mo}+\mathrm{Fe})=0.1$ to form a solid solution and therefore to introduce the oxygen vacancy preferentially at the sites facing to van der Waals gap. Owing to the oxygen vacancy, the substitution of $\mathrm{Mo}$ (VI) with $\mathrm{Fe}(\mathrm{III})$ in $\alpha-\mathrm{MoO}_{3}$ results in remarkable changes as a lithium insertion host, and the open-circuit potential becomes higher and the discharge capacity increases at the same time.

\section{REFERENCES}

1) J. Desilvestro and O. Hass, J. Electrochem. Soc., 137, 5C (1990).

2) J.O. Besenhard, J. Heydecke and H.P. Fritz, Solid State Ionics, 6, 215 (1982).

3) J.O. Besenhard, J.Heydecke, E. Wudy and H.P. Fritz, Solid State Ionics, 8, 61 (1983).

4) F. Bonino, L.P. Bicelli, B. Rivolta, M. Lazzari and F. Festorazzi, Solid State Ionics, 17, 21 (1985).

5) C. Julien, O.M. Hussain, L.E. Farh and M. Balkanski, Solid State lonics, 53-56, 400 (1992).

6) K. Eda, J. Solid State Chem, 83, 292 (1989).

7) N. Sotani, K. Eda and M. Kunitomo, Catal. Soc. Japn., 33, 284 (1991).

8) A.O. Dmitrienko, A.G. Malyakina and A.F. Bol'shakov, Russ. J. Inorg. Chem., 30, 1250 (1985).

9) W.R. McKinnon and R.R. Haering, in "Modem Aspects of Electrochemistry" No.15, ed., R.E. White, J.O'M. Bockris and B.E. Conway, p.235, Plenum Press, New York and London, 1983. 